\title{
Fusion surgery for lumbar spinal stenosis?
}

\author{
Fay E. A. Greenway, Marios C. Papadopoulos \\ Department of Neurosurgery, Atkinson Morley Wing, St George's University Hospital, London, UK \\ Correspondence to: Prof. Marios C. Papadopoulos. Department of Neurosurgery, Atkinson Morley Wing, St George's University Hospital, London \\ SW17 0QT, UK. Email: mpapadop@sgul.ac.uk.
}

Submitted Jun 15, 2016. Accepted for publication Jun 25, 2016.

doi: 10.21037/jss.2016.06.08

View this article at: http://dx.doi.org/10.21037/jss.2016.06.08

Low back pain is a leading cause of disability worldwide and a major source of other medical problems including depression and substance misuse. In 2011-2012, lumbar spinal stenosis was diagnosed in 22,759 people in the UK and over 15,000 operations were performed for decompression of the lumbar spine (UK Hospital Episodes Statistics).

Spinal stenosis is typically caused by degenerative changes of the facet joint and ligamentum flavum leading to narrowing of the spinal canal and associated neural compression. This results in leg pain and neurogenic claudication, thus restricting the patients' walking ability and overall quality of life.

Standard UK neurosurgical training for the management of lumbar canal stenosis has been for decompressive laminectomy with undercutting facetectomy to clear the lateral recesses. Concurrent fusion is only performed if there is evidence of dynamic instability on flexion/extension radiographs. However, there is wide variation in views and practice across the globe, with some centres routinely performing instrumented fusion.

Some studies have suggested that degenerative spondylolisthesis is associated with a risk of progressive instability through the manipulation and destruction of spinal elements during decompressive surgery, and thus that fusion should accompany simple decompression (1-4). However, the validity of these studies has since been questioned $(5,6)$.

Several cohort studies (5,7-10) did not find any substantial benefit of combining fusion with the decompression, even in the presence of spondylolisthesis.

Försth et al. 2016 (11) completed a randomized controlled trial in Sweden, comparing decompression alone with decompression and fusion for patients with lumbar canal stenosis, with and without spondylolisthesis. They conclude that there is no significant difference in the effectiveness of these treatments, and that combining fusion with the decompression adds little value to the patient outcome.

Försth et al. randomly assigned 247 patients between the ages of 50 and 80 with lumbar spinal stenosis, with or without degenerative spondylolisthesis, to undergo either decompression alone or decompression with fusion surgery. Two hundred and twenty eight patients were included in the per-protocol analysis-111 had fusion with decompression and 117 had decompression alone. The patients were stratified into fusion with spondylolisthesis, fusion without spondylolisthesis, decompression with spondylolisthesis, and decompression without spondylolisthesis.

One point of note is that assessment of spondylolisthesis was performed using lateral radiographs-without dynamic views. This is contrary to our practice where we would typically use flexion and extension views as part of the work up process to help decide management. They defined degenerative spondylolisthesis as the presence of forward slip of a vertebra of at least $3 \mathrm{~mm}$ in relation to the vertebra below it.

The primary outcome measure was the Oswestry Disability Index (ODI), an internationally recognised and validated measure used to assess disability related to low back pain. Two-year outcomes showed no statistically significant difference between the treatment groups with a mean score of 27 for fusion-decompression group versus 24 for decompression alone. When stratified into the presence or absence of spondylolisthesis, outcomes were similar to the overall analysis. Further post-hoc analysis of the spondylolisthesis group showed no significant difference in ODI score between the fusion-decompression versus the decompression alone groups at baseline pre-op or at 2 years. 
There was no significant difference in results of the six minute walking test at 2 years, or in the walking distance between the two groups.

One hundred and forty four patients were eligible for inclusion in the five year follow up assessment, of those 138 provided information. There was no significant difference between the fusion-decompression and the decompression alone groups; and results were similar with and without spondylolisthesis.

In the same issue of NEJM, Ghogawala et al. (12) published their data on the same subject. This was a randomised controlled trial assigning 66 patients, between the ages of 50 and 80 , to either decompression alone or decompression and fusion. However, this trial only included patients with grade I spondylolisthesis, as seen on lateral lumbar radiographs. Their primary outcome measure was the physical component score of the SF-36 questionnaire and secondary outcome the ODI. The SF-36 physical component score is a section of the internationally validated Medical Outcomes Study 36-item Short Form Heath Survey-a survey completed by the patient themselves. The improvement in the physical component SF36 scores between the groups was significantly different, with the fusion group having a greater improvement $(\mathrm{P}=0.046)$. The ODI score differences between the two groups were not statistically significant.

As one might expect, the rate of complications in fusiondecompression surgery was higher than decompression alone. A large analysis of registry data showed the addition of fusion doubled the risk of severe adverse events (13). In addition to the complication rate, length of hospital stay and costs associated with fusion should also be considered. All healthcare systems have financial and economic pressures; one should bear this in mind when planning services to ensure that the best, evidence-based, cost-effective treatments are offered.

Försth et al. reported dural tears in $11 \%$ for both the fusion-decompression and decompression alone groups. Though not statistically significant, post-operative wound infections requiring antibiotics alone occurred in $10 \%$ of the fusion-decompression group and in $4 \%$ of the decompression alone group.

Both Försth and Ghogawala demonstrated statistically significant differences in regards to blood loss and operating times (Ghogawala-blood loss: fusiondecompression $513 \mathrm{~mL} v s$. decompression alone $83 \mathrm{~mL}$; operating time: fusion-decompression 289 minutes $v s$. decompression alone 124 minutes; P values <0.001)
(Försth—blood loss: 686 vs. $311 \mathrm{~mL}$; operating time: 149 vs. 95 minutes; $\mathrm{P}$ values $<0.01$ ).

Longer operating times with greater blood loss in older patients with comorbidities may make fusion less favourable, though one could also argue that subjecting a patient to one longer operation may be preferable to the potential requirement for a second operation at a later date.

Hospitalisation was significantly longer in the fusiondecompression patients compared with the decompression alone (Försth—7.4 vs. 4.1 days, Ghogawala — 4.2 vs. 2.6 days; $\mathrm{P}$ value $<0.001)$.

Försth et al. reported mean operation costs of US $\$ 12,200$ in the fusion-decompression group and $\$ 5,400$ in decompression alone. There will be multiple reasons for this including additional operating time, extended hospitalization, and cost of implants. At two year follow up, the study investigators also looked at the number of visits to doctors, to other health care professionals, number of days receiving benefits, and the number of patients still using analgesics for back problems. However, these results were not statistically significant.

Whilst in an ideal world the economic status of a country's healthcare system should not bear any influence on the decision for optimal treatment, the costs of interventions cannot be ignored. A procedure which is known to cost significantly more than another, e.g., spinal fusion, must be supported by conclusive evidence for a positive impact on patient outcome compared with a less costly alternative.

One of the issues with surgery for lumbar spinal stenosis is the notion of avoidance of a second operation. There are two issues in particular. The first is the concept that decompression surgery alone may increase the likelihood of instability requiring fusion at a later date. Nowadays, this can be easily addressed by minimally invasive fusion (14). The second is the recognised risk of accelerated degenerative changes at levels adjacent to the fused segment. Thus, data on reoperation rates is needed to justify management decisions.

In Försth's study the frequency of subsequent surgery did not differ between treatment groups. At a mean follow up of 6.5 years $22 \%$ of fusion patients required reoperation and $21 \%$ in the decompression alone group. The reason for further surgery was usually further degenerative disease. In the decompression only group degenerative changes typically occurred at the same level as the initial surgery, but in the fusion group it was, as expected, adjacent level disease.

However, Ghogawala et al. had a significantly greater 
rate of reoperation than Försth. At 4 years follow up 34\% of the decompression alone group underwent further surgery (fusion), compared to the $21 \%$ at 6.5 years in the Swedish study (Försth et al.). Only 14\% of the fusion group required revision surgery (at adjacent levels). This was a statistically significant result, with a $\mathrm{P}$ value of 0.05 . The reasons for this difference are not clear. It is possible that there are differences in practice between the USA and Sweden. One might understand a surgeon's reluctance to perform revision surgery on a patient already fused, hence a lower reoperation rate in the fusion group; whilst being less cautious about offering revision surgery to those who have only had decompression previously, hence a higher reoperation rate. However, one can only speculate and more studies with long term follow up are needed to definitively assess reoperation rates.

As Försth's paper states, the recent increased use of fusion to supplement decompression of the neural structures with laminectomy has been with the intention of minimizing potential risk of future instability and deformity. The key word here is potential. Current evidence does not conclusively demonstrate that patients who undergo simple laminectomy go on to have problems with instability or deformity impacting on their quality of life.

Based on the current evidence available, simple decompressive laminectomy for lumbar spinal stenosis should remain the mainstay of clinical practice, with fusion reserved only for cases of proven spinal instability. There is a risk of trying to fix everything, even if not broken. When a simple operation will do, as suggested by the current available literature, why make it more difficult?

\section{Acknowledgements}

None.

\section{Footnote}

Conflicts of Interest: The authors have no conflicts of interest to declare.

Comment on: Försth P, Ólafsson G, Carlsson T, et al. A Randomized, Controlled Trial of Fusion Surgery for Lumbar Spinal Stenosis. N Engl J Med 2016;374:1413-23.

\section{References}

1. Bridwell KH, Sedgewick TA, O'Brien MF, et al. The role of fusion and instrumentation in the treatment of degenerative spondylolisthesis with spinal stenosis. J Spinal Disord 1993;6:461-72.

2. Fox MW, Onofrio BM, Onofrio BM, et al. Clinical outcomes and radiological instability following decompressive lumbar laminectomy for degenerative spinal stenosis: a comparison of patients undergoing concomitant arthrodesis versus decompression alone. J Neurosurg 1996;85:793-802.

3. Herkowitz HN, Kurz LT. Degenerative lumbar spondylolisthesis with spinal stenosis. A prospective study comparing decompression with decompression and intertransverse process arthrodesis. J Bone Joint Surg Am 1991;73:802-8.

4. Johnsson KE, Redlund-Johnell I, Udén A, et al. Preoperative and postoperative instability in lumbar spinal stenosis. Spine (Phila Pa 1976) 1989;14:591-3.

5. Martin CR, Gruszczynski AT, Braunsfurth HA, et al. The surgical management of degenerative lumbar spondylolisthesis: a systematic review. Spine (Phila $\mathrm{Pa}$ 1976) 2007;32:1791-8.

6. Vaccaro AR, Garfin SR. Degenerative lumbar spondylolisthesis with spinal stenosis, a prospective study comparing decompression with decompression and intertransverse process arthrodesis: a critical analysis. Spine (Phila Pa 1976) 1997;22:368-9.

7. Försth P, Michaëlsson K, Sandén B. Does fusion improve the outcome after decompressive surgery for lumbar spinal stenosis?: A two-year follow-up study involving 5390 patients. Bone Joint J 2013;95-B:960-5.

8. Munting E, Röder C, Sobottke R, et al. Patient outcomes after laminotomy, hemilaminectomy, laminectomy and laminectomy with instrumented fusion for spinal canal stenosis: a propensity score-based study from the Spine Tango registry. Eur Spine J 2015;24:358-68.

9. Rampersaud YR, Fisher C, Yee A, et al. Health-related quality of life following decompression compared to decompression and fusion for degenerative lumbar spondylolisthesis: a Canadian multicentre study. Can J Surg 2014;57:E126-33.

10. Sigmundsson FG, Jönsson B, Strömqvist B. Outcome of decompression with and without fusion in spinal stenosis with degenerative spondylolisthesis in relation to preoperative pain pattern: a register study of 1,624 patients. Spine J 2015;15:638-46.

11. Försth P, Ólafsson G, Carlsson T, et al. A Randomized, Controlled Trial of Fusion Surgery for Lumbar Spinal Stenosis. N Engl J Med 2016;374:1413-23. 
12. Ghogawala Z, Dziura J, Butler WE, et al. Laminectomy plus Fusion versus Laminectomy Alone for Lumbar Spondylolisthesis. N Engl J Med 2016;374:1424-34.

13. Deyo RA, Mirza SK, Martin BI, et al. Trends, major medical complications, and charges associated with surgery for lumbar spinal stenosis in older adults. JAMA

Cite this article as: Greenway FE, Papadopoulos MC. Fusion surgery for lumbar spinal stenosis? J Spine Surg 2016;2(2):154157. doi: 10.21037 /jss.2016.06.08
2010;303:1259-65.

14. Mobbs RJ, Phan K, Malham G, et al. Lumbar interbody fusion: techniques, indications and comparison of interbody fusion options including PLIF, TLIF, MI-TLIF, OLIF/ATP, LLIF and ALIF. J Spine Surg 2015;1:2-18. 